\title{
A Multi-Classifier Approach of EMG Signal Classification for Diagnosis of Neuromuscular Disorders
}

\author{
Muzaffar Khan \\ S.S.S.I. Research \& Tech \\ Sehore Bhopal (M.P) India
}

\author{
Jaikaran Singh \\ S.S.S.I. Research \& Tech \\ Sehore Bhopal (M.P) India
}

\author{
Mukesh Tiwari \\ S.S.S.I. Research \& Tech \\ Sehore Bhopal (M.P) India
}

\begin{abstract}
Electromyographic (EMG) signal provide a significant source of information for diagnosis, treatment and management of neuromuscular disorders. This paper is aim at introducing an effective multi-classifier approach to enhance classification accuracy. The proposed system employs both time domain and time-frequency domain features of motor unit action potentials (MUAPs) extracted from an EMG signal. Different classification strategies including single classifier and multiple classifiers with time domain and time frequency domain features were investigated. Support Vector Machine (SVM) and K-nearest neighborhood (KNN) classifier used predict class label ( Myopathic, Neuropathic, or Normal ) for a given MUAP. Extensive analysis was performed on clinical EMG database for the classification of neuromuscular diseases and it is found that the proposed methods provide a very satisfactory performance in terms overall classification accuracy.
\end{abstract}

\section{Keywords}

Support Vector Machine, EMG; Discrete wavelet Transform; K-nearest neighborhood (KNN)

\section{INTRODUCTION}

Electromyographic (EMG) signal analysis plays a major role in the diagnosis of neuromuscular diseases, such as amyotrophic lateral sclerosis (ALS) and myopathy. Neuromuscular diseases changes, the shape and characteristics of the motor unit action potentials (MUAPs) and firing patterns of the motor unit (MU) are affected. . MUAPs detected from myopathic patients are characterized by high frequency contents, low peak-to-peak amplitude and MUAPs neuropathic patients are poly-phasic, low frequency, high peak-to-peak amplitude than the normal MUAPs. [1], [2]. The amplitude and time and frequency domain properties of the surface EMG signal are dependent on the timing and intensity of muscle contraction. When a patient maintains low level of muscle contraction, individual MUAPs can be easily recognized. As contraction intensity increases, more motor units are Different MUAPs will overlap, causing an interference pattern in which the neurophysiologist cannot detect individual MUAP shapes reliably [3]. The methods reported in [1], [11] used wavelet-domain features extracted through multi-level decomposition using a filter bank structure consisting of only the analysis bank with Daubechies 4 wavelet filters, and several time domain features are used, such as zero crossing rate, turns-amplitude ratio, root-meansquare (RMS) value and autoregressive (AR) coefficients [13], [14]. Several classification methods such as fusion classifier, multi-classifier, an SVM that provides such probabilities for each class is reported in [1], [16]. Existing EMG signal decomposition methods can successfully decompose EMG signals extracting MUAPs by dominant MUAP selection method or thresholding active and nonactive region [24], [26] . The motor unit potential trains (
MUPT) is assumed to have MUP shape validity, if motor unit MU discharges corresponding to a valid MUPT occur at regular intervals and in general, have a Gaussian-shaped interdischarge interval (IDI ) histogram [16],[27],[28]. Empirical mode decomposition (EMD) is a kind of self-adapting signal processing method and it is very suitable for dealing with nonlinear and non-stationary signals, a new method is proposed which combines independent component analysis, empirical mode decomposition and AR model to extract and analyze the surface EMG. EMD plus AR model shows superior accuracy of $93 \%$ compared to AR model having accuracy $85 \%$ [3]. Sarbast Rasheed et al. [10], present design methodology for integrating heterogeneous classifier ensembles by employing a diversity-based hybrid classifier fusion approach, whose aggregator module consists of two classifier combiners, to achieve an improved classification performance for motor unit potential classification during electromyographic (EMG) signal decomposition. The pool of base classifiers consists of different kinds of classifiers the adaptive certainty-based, the adaptive fuzzy k-NN, and the adaptive matched template filter classifiers. Miki Nikoli et al. [33], developed the system which decomposes signal decomposition algorithm consists of three stages, segmentation, clustering, and resolution of compound segments. Clustering of Segments is determined if two segments are similar in shape, a so called distance measure is used.

In this paper, DWT based feature extraction schemes are proposed for the classification of normal, ALS and myopathy subjects. First an MUAP based scheme is proposed where the MUAPs are first extracted from the EMG data by using a decomposition technique. A dominant MUAP selection criterion is introduced to extract features only from selected MUAPs. Statistical features are obtained from the DWT of dominant MUAPs. Next design of multi-classifier majority voting using SVM as base classifier and K-nearest neighborhood (KNN) classifier is employed. Finally, experimental results with comparative analysis are presented.

\section{MUAP EXTRACTION BY USING EMG DECOMPOSITION}

The first step is the filtering part, in which the EMG signal is band pass filtered (10 Hz to $3 \mathrm{kHz}$ ). Now EMG signal contain so-called inactive segments with low activity and active segments containing MUAPs. Window function is used extract MUAPs around the peak this low activity segments can affect time domain feature. So it removed in beginning before applying window function. To remove inactive segment threshold parameter $( \pm \lambda)$ is set around baseline if the signal sample lays between $+\lambda$ and $-\lambda$ for more than $0.4 \mathrm{~ms}$ is discarded. Segmentation of EMG signals carried by finding the peaks of the MUAPs, then a window of 180 sampling points is centered at the identified peak, size of window depends on sampling rate [23]. The selection criteria 
for the MUAP extracted from EMG signal is based on dominant MUAP based on temporal energy. In case of myopathy MUAPs become low in amplitude and short in duration, while for the neurogenic disorders, MUAPs exhibit higher amplitude and longer duration than normal. Hence, the energy content of MUAPs provide significant information about the EMG signal and idea about pathology. ALS group is the highest followed by the normal group and the myopathic dominant MUAP has the lowest energy. Once the dominant MUAPs for different datasets are obtained, these are then used for the feature extraction [19].

\section{TIME AND TIME-FREQUENCY FEATURE EXTRACTION AND SELECTION NORMAL}

\subsection{Time Domain Features Extraction}

Time domain features are morphological features of the MUAPs which are used for visual assessment. MUAPs myopathic patients are characterized by high frequency contents, low peak-to-peak amplitude. Neuropathic patients are poly-phasic, low frequency, high peak-to-peak amplitude than the normal MUAPs. The following morphological features were employed to represent each MUAP [1], [20], [21].

1. Rise Time: The time between the initial positive to the next negative peak within the main spike.

2. Ratio of Peak to Peak magnitude to RMS value

3. Spike Duration: The time between the first to the last positive peak.

4. Ratio of ascending slope to descending slope positive spike of MUAP.

5. Ratio Area of positive to Area of negative spike MUAP

6. Phases: The number of baseline crossings where amplitude exceeds $\pm 25 \mu \mathrm{V}$, plus one.

7. Thickness: The ratio of the area to the peak-to-peak amplitude.

8. Peak-to-Peak Samples Number: Total number of samples between the minimum positive and the maximum negative peak.

\subsection{DWT Based Feature Extraction Scheme}

The DWT is a multi-resolution technique that offers localization both in time and frequency. Hence, the DWT is chosen to extract features from the EMG signal

The DWT of a signal S(n) can be represented as

$$
\begin{aligned}
& \mathrm{W}_{\varphi}\left(\mathrm{j}_{0}, \mathrm{~K}\right)=\frac{1}{\sqrt{\mathrm{M}}} \sum_{\mathrm{n}} \mathrm{s}(\mathrm{n}) \varphi_{\mathrm{j}_{0}, \mathrm{~K}}(\mathrm{n}) \\
& \mathrm{W}_{\psi}(\mathrm{j}, \mathrm{K})=\frac{1}{\sqrt{\mathrm{M}}} \sum_{\mathrm{n}} \mathrm{s}(\mathrm{n}) \psi_{\mathrm{j}, \mathrm{K}}(\mathrm{n})
\end{aligned}
$$

where, $\mathrm{j} \geq \mathrm{j}_{0}$ and $\mathrm{s}(\mathrm{n}), \varphi_{\mathrm{j}_{0}, \mathrm{~K}}(\mathrm{n}), \psi_{\mathrm{j}, \mathrm{K}}(\mathrm{n})$ are functions of discrete variables $n=0,1 \ldots \ldots . . . M-1$ select $\mathrm{M}$ to be a power of $2\left(\mathrm{M}=2^{j}\right), \mathrm{K} \epsilon \mathrm{Z}, \mathrm{j} \in \mathrm{N}$ Equation (1) computes the approximation coefficients and equation (2) computes the detail coefficients

The original signal being filtered via high pass $\mathrm{W}_{\psi}(\mathrm{j}, \mathrm{K})$ and a low-pass $\mathrm{W}_{\varphi}\left(\mathrm{j}_{0}, \mathrm{~K}\right)$ filter produces output expressed as

$$
\begin{aligned}
& \mathrm{W}_{\varphi}\left(\mathrm{j}_{0}, \mathrm{~K}\right)=\frac{1}{\sqrt{M}} \sum_{n} s(n) 2^{j / 2} \sum_{m} h_{\psi}(m-2 k) \sqrt{2} \varphi\left(2^{j+1}, \mathrm{n}-\mathrm{m}\right) \ldots 3 \\
& \mathrm{~W}_{\varphi}\left(\mathrm{j}_{0}, \mathrm{~K}\right)=\frac{1}{\sqrt{\mathrm{M}}} \sum_{\mathrm{n}} \mathrm{s}(\mathrm{n}) 2^{\mathrm{j} / 2} \sum_{\mathrm{m}} \mathrm{h}_{\psi}(\mathrm{m}-2 \mathrm{k}) \sqrt{2} \varphi\left(2^{\mathrm{j}+1} \mathrm{n}-\mathrm{m}\right) \\
& \mathrm{W}_{\varphi}\left(\mathrm{j}_{0}, \mathrm{~K}\right)=\sum_{m} h_{\psi}(m-2 k) \mathrm{W}_{\varphi}(j+1 \mathrm{k}) \\
& \text { Similarly, } \mathrm{W}_{\psi}(\mathrm{j}, \mathrm{K}) \text { is written as }
\end{aligned}
$$$$
\mathrm{W}_{\psi}(\mathrm{j}, \mathrm{K})=\sum_{m} h_{\varphi}(m-2 k) \mathrm{W}_{\varphi}(j+1 \mathrm{k})
$$

DWT coefficients at adjacent scales. Both $\mathrm{W}_{\varphi}\left(\mathrm{j}_{0}, \mathrm{~K}\right)$ and $\mathrm{W}_{\psi}(\mathrm{j}, \mathrm{K})$ are obtained by convolving the scale $(\mathrm{j}+1)$ approximation coefficient $\mathrm{W}_{\varphi}(j+\mathrm{k})$ with $h_{\varphi}(-n)$ and $h_{\psi}(-n)$ respectively and then subsampling the convolved output by a factor of 2 .

\subsection{Mother Wavelet Selection}

In this work, the best mother wavelet was determined experimentally using cross validation technique. The choice of mother wavelet can be based on it can be selected based on correlation $\gamma$ between the signal of interest and the wavelet denoised signal. It determines estimation of the original signal, but also affect the frequency spectrum of the de-noised signal

$$
\gamma=\sum \frac{(X-\bar{X})(Y-\bar{Y})}{(X-\bar{X})^{2}(Y-\bar{Y})^{2}} \quad \ldots . .7
$$

Where $\bar{X}$ and $\bar{Y}$ are mean value of set $\mathrm{X}$ and Y, respectively. The family of five mother wavelets consisting of Symlet, Daubechies, Morlet, Coiflet and Haar were studied .Symlet4 and Daubechies4 provided the most discriminative frequency band for three groups (myopathic, neuropathic, and normal). The DWT is a multi-resolution technique that offers localization both in time and frequency [17].

\subsection{DWT Features Reduction.}

Once the best discriminative frequency band was determined, the following statistics were estimated and used to represent the time-frequency distribution of the isolated MUAPs and reduce the dimension of DWT features [19].

1) Mean of the absolute values of the coefficients in each sub- band.

2) Average power of the wavelet coefficients in each sub -band.

3) Standard deviation of the coefficients in each subband

\section{CLASSIFICATION STRATEGIES}

In this paper, Multi- Classifiers Majority Voting (MCMV) classification strategies were evaluated. Multi classifier as shown in figure 1, consist three group in parallel. Each group consist of four SVM classifier as base classifier, two scheme is employed for class discrimination one against one (OAO) and one against all (OAA) given in table 1, [29], [30]. The selected SVM has Gaussian radial basis function (RBF) kernel, which is stated as follows

$K\left(x, x^{\prime}\right)=e^{-\gamma /\left|x-x^{\prime}\right|^{2}}$

Where $\mathrm{x}$ the input feature vector to the SVM, $x^{\prime}$ is the center of the support vectorand $\gamma$ is the width of the kernel [1]. The multi-classifier scheme base classifier $\mathrm{C} 1$ to $\mathrm{C} 12$ are grouped into three groups, the first group consist base classifier from 
C1 to C4 (myopathic class label), second group consist base classifier from C5 to C68(Neuropathic group) and third group consist of base classifier from C9 to C12 (Normal class label). SVM was first trained as a standard SVM and then a sigmoid function was trained which maps the SVM outputs to the posterior probabilities. The conditional probabilities of the two classes for given input vector $\mathrm{x}$ is given by

$$
\begin{gathered}
P 1(x)=\frac{1}{1+\exp (\beta 1 \cdot f(x)+\beta 2} \\
\mathrm{P} 2(\mathrm{x})=1-\mathrm{P} 1(\mathrm{x})
\end{gathered}
$$

$\mathrm{f}(\mathrm{x})$ is the output standard SVM, where $\beta 1$ and $\beta 2$ are parameter of sigmoid function, these parameters are derived from maximum likelihood estimation during training phase.

Table 1. List of Base Classifiers with Time Frequency

\begin{tabular}{|c|c|c|c|}
\hline $\begin{array}{l}\text { Base } \\
\text { classifier }\end{array}$ & $\begin{array}{l}\text { Priority } \\
\text { Ranking }\end{array}$ & $\begin{array}{l}\text { Class } \\
\text { Discrimination }\end{array}$ & $\begin{array}{l}\text { Group/Class } \\
\text { label }\end{array}$ \\
\hline $\mathrm{C} 1$ & P1 & $\begin{array}{l}\text { Myopathic Vs. } \\
\text { Others (Normal } \\
\text { \& Neuropathic) }\end{array}$ & \multirow[t]{4}{*}{$\begin{array}{l}\text { Group1 } \\
\text { Myopathic }\end{array}$} \\
\hline $\mathrm{C} 2$ & P2 & $\begin{array}{l}\text { Myopathic Vs. } \\
\text { Myopathic }\end{array}$ & \\
\hline C3 & P3 & $\begin{array}{l}\text { Myopathic Vs. } \\
\text { Neuropathic } \\
\text { (inverted votes) }\end{array}$ & \\
\hline $\mathrm{C} 4$ & P3 & $\begin{array}{l}\text { Myopathic Vs. } \\
\text { Normal } \\
\text { (inverted votes) }\end{array}$ & \\
\hline C5 & $\mathrm{P} 1$ & $\begin{array}{l}\text { Neuropathic Vs. } \\
\text { Others (Normal } \\
\text { \& Myopathic) }\end{array}$ & \multirow[t]{4}{*}{$\begin{array}{l}\text { Group2 } \\
\text { Neuropathic }\end{array}$} \\
\hline C6 & P2 & $\begin{array}{l}\text { Neuropathic Vs. } \\
\text { Neuropathic }\end{array}$ & \\
\hline C7 & P3 & $\begin{array}{l}\text { Neuropathic Vs. } \\
\text { Myopathic } \\
\text { (inverted votes) }\end{array}$ & \\
\hline $\mathrm{C} 8$ & P3 & $\begin{array}{l}\text { Neuropathic } \\
\text { Vs. Normal } \\
\text { (inverted votes) }\end{array}$ & \\
\hline C9 & $\mathrm{P} 1$ & $\begin{array}{l}\text { Normal Vs. } \\
\text { Others } \\
\text { (Myopathic \& } \\
\text { Neuropathic) }\end{array}$ & \multirow[t]{4}{*}{$\begin{array}{l}\text { Group3 } \\
\text { Normal }\end{array}$} \\
\hline $\mathrm{C} 10$ & P2 & $\begin{array}{l}\text { Normal Vs } \\
\text { Normal }\end{array}$ & \\
\hline C11 & P3 & $\begin{array}{l}\text { Normal Vs. } \\
\text { Neuropathic } \\
\text { (inverted votes) }\end{array}$ & \\
\hline $\mathrm{C} 12$ & P3 & $\begin{array}{l}\text { Normal Vs. } \\
\text { Myopathic } \\
\text { (inverted votes) }\end{array}$ & \\
\hline
\end{tabular}
Feature Employed

\subsection{Majority Voting}

The group with more votes is selected as the ultimate decision. The votes of base classifier trying classify other than its group label are inverted for majority voting method to be used However, in the case of equal number of votes between two groups, then decision is based two top priority classifier within the group. Classifier with priority P1 is highest and P3 is lowest.

\subsection{Distance weighted k-Nearest Neighborhood (D WKNN)}

DWKNN is treated as a benchmark classifier employed for the purpose of comparison. K-nearest neighbor has an identical weight in decision making, and neglects that closer nearest neighbor contribute more to classification. Dudani proposed the weight the distance weighted k-Nearest Neighbor (KNN) rule (WKNN) in which votes of the different members of the one of the $\mathrm{K}$ neighbors set are computed by the function of their distance to the query [31]. In this scheme, the $\mathrm{i}$-th weight of the corresponding nearest neighbor is given as

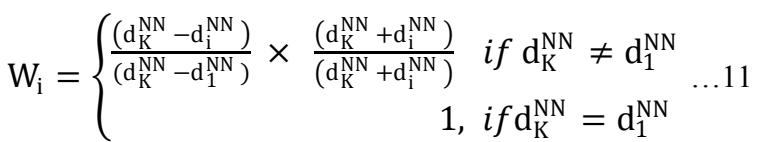

Where $\mathrm{d}_{\mathrm{i}}^{\mathrm{NN}}$ is the distance to the query of the i-th nearest neighbor $d_{1}^{N N}$ is the distance the nearest neighbor and $d_{K}^{N N}$ is the distance of the K-furthest neighbor. Then, the query is assigned to the majority weighted voting class label $y_{\text {jmax }}$ using the following rule

$$
y_{j \max }=\arg \max _{y i} \sum_{\left(x_{i}, y_{i}\right) \varepsilon T} W_{i} \times I\left(y=y_{i}^{N N}\right)
$$

Algorithm for DWKNN can be state as

1. Compute the distances of nearest neighbors of the query $\bar{x}$.

2. Sort the distances in an ascending order.

3. Calculate the dual weights of $k$ nearest neighbors, $\bar{W}=\left\{\overline{w_{1}}, \ldots \ldots, \overline{w_{k}}\right\}$ from equation 11 .

4. Assign a majority weighted voting class label $y_{\text {jmax }}$ to the query $\bar{x}$.

\subsection{Evaluation Methodology}

The performance of classifiers is evaluated using indices, Classification accuracy indices is defined for this purpose: accuracy for classifier (Ac), indices is given by

$$
A c=\frac{\text { Number of correctly Classified EMG }}{\text { Total number EMG sample }} \ldots \ldots . . .13
$$

Misclassification of classifier is given by (Mc) is given by $\mathrm{M} c=\frac{\text { Number of } \text { Misclassified EMG Class label }}{\text { Total number EMG sample / class Label }} \ldots . .14$ 
RAW EMG SIGNAL

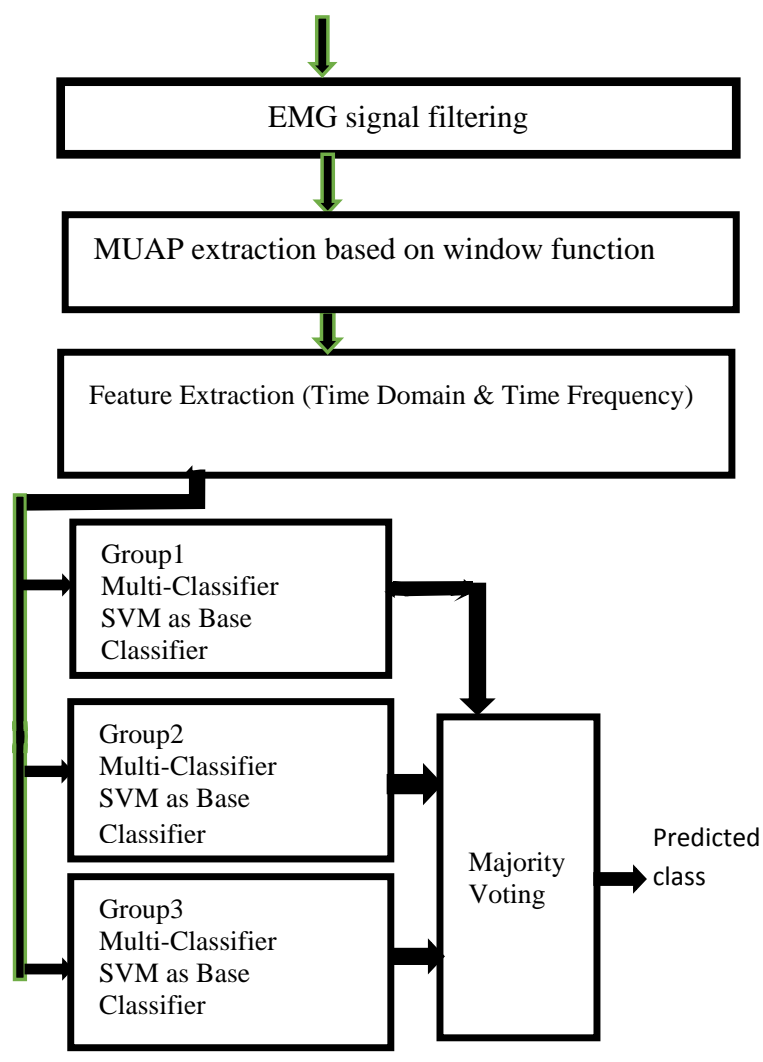

Figure 1: Structure of Proposed multi-classifier

\section{RESULTS AND DISCUSSION}

As it seen from graph shown in figure 2 and Table 2 classification accuracy is high within the same class. Whereas classification strategy one against all class label gives second highest accuracy for base classifier in all groups. The proposed multi-classifier model provides average accuracy 97\% for time-frequency feature and WKNN Classifier achieved classification accuracy $95 \%$. Both the models were tested on data of 150 EMG signal ,50 sample of each class The segmentation of EMG is carried by remove inactive region around base line and use of window function around peak gives simple approach for MAUPS extraction. The dominant MAUPs selected for Time and Time-frequency domain feature extraction. The base classifier used in the multi-classifier model is trainable, a sigmoid function was trained which maps the SVM outputs to the posterior probabilities. All posterior probabilities are sorted in descending order, then from posterior values related to misclassified vector, threshold value for misclassified bound selected. Time-frequency domain features are selected since time domain feature fail to map spectrum behavior and complexity of EMG signal. The only differences are that on the one hand, DWKNN offers a large variety of possible kernel functions in order to produce different weighting schemes. The main purpose of this extended method is to gain a technique that up to a certain degree is independent of a bad choice for $k$ resulting in a high misclassification error. Now this number of nearest neighbors is implicitly hidden in the weights. DWKNN classifiers aggregated by a (weighted) majority vote and this aggregated result is used as prediction.

\section{Group 1 Myopathic}

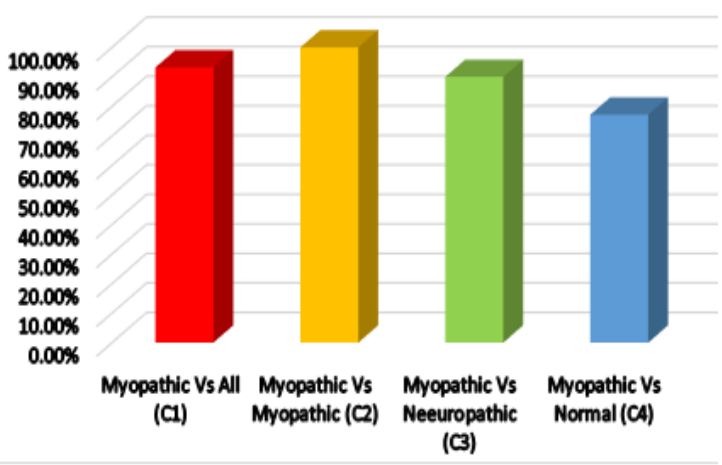

Group 2 Neuropathic

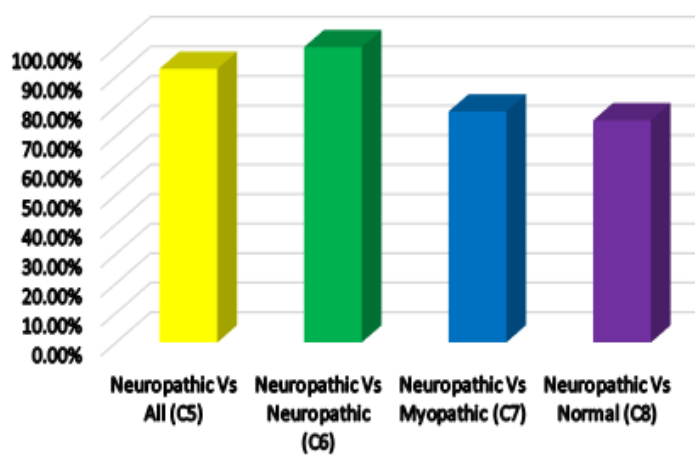

Group 3 Normal

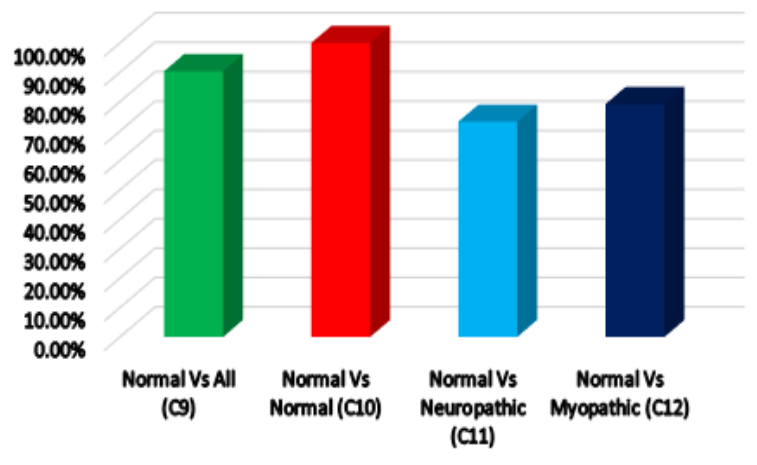

Multi-Classifier Model \& DWKNN

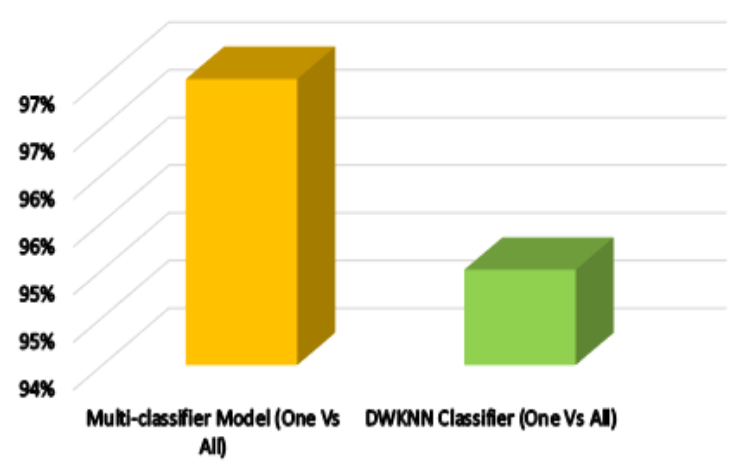

Figure 2: -Accuracy of base classifier of Multi-classifier 
Table No 2: Class discrimination and percentage Accuracy of Classifier

\begin{tabular}{|l|l|l|}
\hline Base classifier & $\begin{array}{l}\text { Class } \\
\text { Discrimination }\end{array}$ & $\begin{array}{l}\text { Percentage } \\
\text { Accuracy }\end{array}$ \\
\hline C1 & $\begin{array}{l}\text { Myopathic Vs } \\
\text { Others }\end{array}$ & $93.21 \%$ \\
\hline C2 & $\begin{array}{l}\text { Myopathic Vs } \\
\text { Myopathic }\end{array}$ & $100 \%$ \\
\hline C3 & $\begin{array}{l}\text { Myopathic Vs } \\
\text { Neeuropathic }\end{array}$ & $90 \%$ \\
\hline C4 & $\begin{array}{l}\text { Myopathic Vs } \\
\text { Normal }\end{array}$ & $77.21 \%$ \\
\hline C5 & $\begin{array}{l}\text { Neuropathic Vs } \\
\text { Others }\end{array}$ & $96.2 \%$ \\
\hline C6 & $\begin{array}{l}\text { Neuropathic Vs } \\
\text { Neuropathic }\end{array}$ & $100 \%$ \\
\hline C7 & $\begin{array}{l}\text { Neuropathic Vs } \\
\text { Myopathic }\end{array}$ & $78.2 \%$ \\
\hline C8 & $\begin{array}{l}\text { Neuropathic Vs } \\
\text { Normal }\end{array}$ & $75.21 \%$ \\
\hline C9 & Normal Vs Others & $90.38 \%$ \\
\hline C10 & Normal Vs Normal & $100 \%$ \\
\hline C11 & $\begin{array}{l}\text { Normal Vs } \\
\text { Neuropathic }\end{array}$ & $73.21 \%$ \\
\hline C12 & $\begin{array}{l}\text { Normal Vs } \\
\text { Myopathic }\end{array}$ & $79.2 \%$ \\
\hline $\begin{array}{l}\text { Multi-classifier } \\
\text { Model }\end{array}$ & One Vs All & $97 \%$ \\
\hline $\begin{array}{l}\text { DWKNN } \\
\text { Classifier }\end{array}$ & One Vs All \\
\hline
\end{tabular}

Table 3: Classification Accuracy of DWKNN Classifier

\begin{tabular}{|l|l|l|l|}
\hline S.No & Class Label & Feature type & $\begin{array}{l}\text { Percentage } \\
\text { accuracy }\end{array}$ \\
\hline 1 & $\begin{array}{l}\text { Neuropathic } \\
\text { Vs All }\end{array}$ & $\begin{array}{l}\text { Time domain \& } \\
\text { Frequency domain }\end{array}$ & $97.00 \%$ \\
\hline 2 & $\begin{array}{l}\text { Myopathic Vs } \\
\text { All }\end{array}$ & $\begin{array}{l}\text { Time domain \& } \\
\text { Frequency domain }\end{array}$ & $92.00 \%$ \\
\hline 3 & $\begin{array}{l}\text { Normal Vs } \\
\text { All }\end{array}$ & $\begin{array}{l}\text { Time domain \& } \\
\text { Frequency domain }\end{array}$ & $96.00 \%$ \\
\hline \multicolumn{2}{|l|}{ Average Accuracy } & 95.00 \\
\hline
\end{tabular}

\section{CONCLUSION}

This paper focuses on evaluating two classification strategies to classify the MUAPs into the following classes, normal, myopathic and neuropathic. The proposed classification strategies consist of several base classifiers which take different MUAPs features such as time domain features, timefrequency features (wavelet coefficients), These classification strategies can be employed in other pattern recognition applications because they segment a big decision into several detailed decisions where the input of each decision node can be separately optimized. Multi-classifier overcomes limitation of single stage classifier but with a cost of complexity and processing time. Although the result of time-frequency features is superior to the time domain ones, selecting both types of feature result in promising results $(97 \%)$ for the three classes. These classification strategies can be employed in other pattern recognition applications. Through our experiments, the proposed method always outperforms the DWKNN classifiers among a large range of $k$ and its effectiveness was demonstrated with good performance. For extending this research is to investigate influence of the recording conditions on the classification accuracy.

\section{ACKNOWLEDGMENTS}

The authors would like to gratefully thank Dr.G.R..Selokar director S.S.S.I.T for sharing research knowledge, guidance and giving access to laboratory facility for the research work.

\section{REFERENCES}

[1]. Tahereh Kamali, Reza Boostani and Hoossein Parsaei, "A Multi-Classifier Approach to MUAP Classification of Neuromuscular Disorders" IEEE Transaction On Neural Systems And Rehabilitation Vol22 No1 January 2014

[2]. Hoosien Parsaei and Daniel .W.Stashul, "EMG Signal Decomposition Using Motor Unit Potential Train Validity” ,IEEE Transaction On Neural Systems And Rehabilitation Vol21 No2 Marchry 2013

[3]. Gurmanik Kaur , A. Arora and V. K. Jain , "EMG Diagnosis using Neural Network Classifier with Time Domain and AR Features", ACEEE International. Journal. on Electrical and Power Engineering, Vol. 01, No. 03, Dec 2010.

[4]. Hossein Parsaei and Daniel W. Stashuk, "EMG Signal Decomposition Using Motor Unit Potential Train Validity", IEEE Transactions On Neural Systems And Rehabilitation Engineering, Vol. 21, No. 2, March 2013.

[5]. Paulito Palmes*, Wei Tech Ang, Ferdinan Widjaja, Louis CS Tan, and Wing Lok Au, "Pattern Mining of Multichannel sEMG for Tremor Classification" ,IEEE Transactions On Biomedical Engineering, Vol. 57, No. 12, December 2010.

[6]. SHANG Xiaojing, TIAN Yantao and LI Yang, "Feature Extraction and Classification of sEMG Based on ICA and EMD Decomposition of AR Model",IEEE Conference on Biomedical Engineering 2011 ISN 978-14577-0321-8/11

[7]. Aaron J. Young, Lauren $\mathrm{H}$ and Smith, Elliott . "Classification of Simultaneous Movements Using Surface EMG Pattern Recognition" IEEE Transactions On Biomedical Engineering, Vol. 60, No. 5, May 2013

[8]. Sarbast Rasheed, Daniel W. Stashuk and Mohamed S. Kamel, "Integrating Heterogeneous Classifier Ensembles for EMG Signal Decomposition Based on Classifier Agreement”, ,IEEE Transactions On Information Technology In Biomedicine, Vol. 14, No. 3, May 2010

[9]. Rami N. Khushaba, "Correlation Analysis of Electromyogram (EMG) Signals for Multi-User Myoelectric Interfaces", IEEE Transactions On Neural Systems And Rehabilitation Engineering, Vol. 11, No. 1, January 2014

[10].Saara M. Rissanen , Markku Kankaanp and Mika P. Tarvainen ," Analysis of EMG and Acceleration Signals for Quantifying the Effects of Deep Brain Stimulation in Parkinson 's disease" ,IEEE Transactions On Biomedical Engineering, Vol. 58, No. 9, September 2011.

[11]. Sarbast Rasheed, Daniel W. Stashuk, and Mohamed S. Kamel. "A Hybrid Classifier Fusion Approach for Motor Unit Potential Classification During EMG Signal Decomposition", IEEE Transactions On Biomedical Engineering, Vol. 54, No. 9, September 2007

[12].Todd R. Farrell and Richard F. ff. Weir, " $A$ Comparison of the Effects of Electrode Implantation and Targeting on 
Pattern Classification Accuracy for Prosthesis Control. ", IEEE Transactions On Biomedical Engineering, Vol. 55, No. 9, September 2008.

[13].E. R. Kandel, J. H. Schwartz, and T. M. Jessell, "Principles of Neural Science", 4 edition. New York: McGraw-Hill, 2000.

[14].L. J. Pino, D. W. Stashuk, S. G. Boe, and T. J. Doherty, "Motor unit potential characterization using pattern discovery” ,Med. Eng. Phys.,vol. 30, pp. 563-573, 2008.

[15].Hossein Parsaei and Daniel W. Stashuk "SVM-Based Validation of Motor Unit Potential Trains Extracted by EMG Signal Decomposition" IEEE Transactions On Biomedical Engineering, Vol. 59, No. 1, January 2012

[16]. K. Englehart, B. Hudgins, and A. Philip, “A waveletbased continuous classification scheme for multifunction myoelectric control," IEEE Trans. Biomed. Eng., vol. 48, no. 3, pp. 302-311, 2001.

[17]. Carlo J. De Luca, L. Donald Gilmore , " Filtering the surface EMG signal: Movement artifact and baseline noise contamination", Journal of Biomechanics 43 (2010) 1573-1579 Science Direct

[18].A. Subasi, "Medical decision support system for diagnosis of neuromuscular disorders using DWT and fuzzy support vector machines". Comput. Biol. Med., vol. 42, pp. 806-815, 2012.

[19].J. V. Basmajian and C. J. de Luca, "Muscles Alive: Their Functions Revealed by Electromyography", 5 ed. Philadelphia, PA: William Wilkins, 1985.

[20].E. R. Kandel, J. H. Schwartz, and T. M. Jessell," Principles of Neural", 2 Science, 4 edition. New York: McGraw-Hill, 2000.

[21].G. L. Sheean, "Quantification of motor unit action potential energy", Clin. neurophysiol vol. 123, no. 3, pp. 621-625, Mar. 2012

[22]. Gurmanik kaur, A. S. Arora and V. K. Jain, "Comparison of the techniques used for segmentation of EMG signals," in Proc. WSEAS Int. Conf. on Mathematical and Computational Methods, Baltimore, USA, pp. 124129, 2009.

[23]. Daniel Zennaro, Peter Wellig, "A Software Package for the Decomposition of Long-Term Multichannel EMG
Signals Using Wavelet Coefficients", IEEE Transactions On Biomedical Engineering, Vol. 50, No. 1, January 2003

[24].Constantinos S. Pattichis and Marios S. Pattichis , "Time-Scale Analysis of Motor Unit Action Potentials," IEEE Transactions On Biomedical Engineering, Vol. 46, No. 11, November 1999.

[25].A. B. M. S. U. Doulah , S. A. Fattah , W.P. Zhu and M. O. Ahmad, "Wavelet Domain Feature Extraction Scheme Based on Dominant Motor Unit Action Potential of EMG Signal for Neuromuscular Disease Classification ." IEEE Transactions On Biomedical Circuits And Systems, Vol. 8, No. 2, April 2014

[26]. H. P. Clamann, "Statistical analysis of motor unit firing patterns in a human skeletal muscle," Biophys. J., vol. 9, no. 10 , pp. 1233-1251, Oct. 1969.

[27].C. T. Moritz, B. K. Barry,M. A. Pascoe, and R.M. Enoka, "Discharge rate variability influences the variation in force fluctuations across the working range of a hand muscle," J. Neurophysiol., vol. 93, no. 5, pp. 2449-2459, May 2005

[28].S. Knerr, L. Personnaz, and G. Dreyfus, "Single-layer learning revisited: A stepwise procedure for building and training a neural network," in Neurocomputing: Algorithms, Architectures and Applications, J. Fogelman, Ed. New York: Springer-Verlag, 1990.

[29]. L. Bottou, C. Cortes, J. Denker, H. Drucker, I. Guyon, L. Jackel, Y. LeCun, U. Muller, E. Sackinger, P. Simard, and V. Vapnik, "Comparison of classifier methods: A case study in handwriting digit recognition," in Proc. Int. Conf. Pattern Recognit., 1994, pp. 77-87.

[30].Dudani.S.A, "The Distance weighted K-Nearest Rule", IEEE Transaction On System Man \&Cybernetic 6,325 327 (1976)

[31].SHANG Xiaojing, TIAN Yantao and LI Yang "Feature Extraction and Classification of sEMG Based on ICA and EMD Decomposition of AR Model", IEEE 978-14577-0321-8/11 @2011

[32].Xu Zhang and Ping Zhou, "High-Density Myoelectric Pattern Recognition Toward Improved Stroke Rehabilitation", IEEE Transactions On Biomedical Engineering, Vol. 59, No. 6, June 20 